\title{
The Study of Formulations as a Key to an Interactional Semantics
}

\author{
Arnulf Deppermann
}

Published online: 5 July 2011

(C) Springer Science+Business Media B.V. 2011

\begin{abstract}
As an Introduction to the Special Issue on "Formulation, generalization, and abstraction in interaction," this paper discusses key problems of a conversation analytic (CA) approach to semantics in interaction. Prior research in CA and Interactional Linguistics has only rarely dealt with issues of linguistic meaning in interaction. It is argued that this is a consequence of limitations of sequential analysis to capture meaning in interaction. While sequential analysis remains the encompassing methodological framework, it is suggested that it needs to be complemented by analyzing semantic relationships between choices of formulation in the interaction, ethnography, and structural techniques of comparing selected options with possible alternatives. The paper describes the methodological approach taken to interactional semantics by the papers in the Special Issue, which analyse practices of generalization and abstraction in interaction as they are accomplished by formulations of prior versions of reference and description.
\end{abstract}

Keywords Conversation analysis · Formulation · Interactional semantics . Membership categorization · Generalization · Abstraction

\section{Why is Semantics Such a Difficult Object for Conversation Analysis?}

Since its beginnings, conversation analysis (CA) has aimed at an analysis of social interaction in terms of accountable conduct which is meaningful for the participants. Still, the primary focus of CA has been on the sequential organization of turn-taking and action. How participants use linguistic and other resources to create meaning and which resources and procedures they use to interpret linguistic forms in context has not figured prominently in CA research yet. Semantic issues in this wider notion

\footnotetext{
A. Deppermann $(\bowtie)$

Institut für Deutsche Sprache (IDS), R 5, 6-13, 68161 Mannheim, Germany

e-mail: deppermann@ids-mannheim.de
} 
(including reference, inferential, evaluative and argumentative aspects of meaning) have been dealt with in some detail in the context of case-analyses, which, however, did not serve to analyze how linguistic meaning is organized in interaction, but to show how some sequentially organized interactive practice works. The situation is rather similar in Interactional Linguistics, where the focus has mostly been on phonetics, prosody and grammar as resources for the organization of talk-ininteraction (see Couper-Kuhlen and Selting 2001; Couper-Kuhlen and Ford 2004; Barth-Weingarten et al. 2010). Only few papers have dealt with lexis and semantics of open-class items (cf. some of the papers in Hakulinen and Selting 2005; Deppermann 2007; Norén and Linell 2007; Linell 2009: ch.15).

Why has the meaning of linguistic structures in conversation a rather peripheral status as an object of study in CA? No conversation analyst would deny that words are systematically used in order to create meaning and that interpretation is incessantly going on in interaction in order to grasp its relevance and to produce a next action. Still, semantics in interaction is a recalcitrant object for conversation analytic research. This is because we are faced with the methodological problem that participants' interpretations mostly surface only in very selective ways as an observable phenomenon in conversation (if they do at all). CA's basic methodological tenet to stick to what participants display (by their reactions) to be relevant severely limits the scope of what can be included in the analysis of meaning. This is so, because although interpretation is at the heart of interaction, it occurs mostly implicitly and en passant, letting often only show conversational effects (in terms of actions) and symptoms (in terms of turn-design, repair, hedging, etc.) without making their semantic, epistemic and inferential grounds explicit.

How can then a conversation analytic approach to meaning in interaction proceed? The papers in this special issue explore ways of dealing with this issue by starting from two questions:

(a) Which conversational phenomena exhibit participants' semantic work in interaction? And how is semantic work organized in terms of interactional and interpretive practice?

(b) In which ways do we have to complement sequential analysis with other methodological procedures in order to account for how meaning is produced and recovered in interaction?

Semantic work in interaction becomes observable if semantics is not only used as a resource, but if participants specify, generalize, correct or negotiate the meaning of some expression (string of lexical items) or some description produced before in that interaction. One such occasion is the production of formulations, which generalize and abstract the meaning of a first version produced before, either by the speaker him/herself or by an interactional partner. Formulations thus give access to how people understand each other and how the words they use are to be understood. Phenomena and practices of interactional semantics related to formulations used to generalize, abstract or specify meanings are the objects of this Special Issue.

In this introduction, I will locate the approach taken by the papers with respect to prior research on formulations and give a short review of general interactional 
properties of formulations ("Formulations as Objects of Research in CA"). In "Studying Interactional Semantics: Sequential Analysis and Beyond," I will turn to methodological considerations having to do with limitations of a CA-approach to interactional semantics and review the suggestions for its extension put forth in this Special Issue. "Semantic Aspects of Formulations" will be devoted to semantic aspects of formulations in general, while "Generalization and Abstraction as Practices of Formulation in Interaction" will deal more specifically with generalization and abstraction as specific practices of formulation.

\section{Formulations as Objects of Research in CA}

In CA, "formulation" has been used for three different, albeit related phenomena.

(a) "Formulation" was first introduced by Garfinkel and Sacks (1970: 351) to refer very broadly to all different kinds of meta-communicative, self-reflexive descriptions in conversation: "We shall speak of conversationalists' practices of saying-in-so-many words-what we-are-doing as formulating". As examples, they state that members may "describe that conversation, (...) explain it, or characterize, or explicate, or translate, or summarize, or furnish the gist of it, or take note of its accordance with rules, or remark on its departure from rules" (Garfinkel and Sacks 1970: 350). This understanding of "formulations" is akin to the term Reformulierung ("reformulation"), which has become an influential concept in German discourse and conversation analysis (Gülich and Kotschi 1996; Bührig 1996; Ciapuscio 2003; Rittgeroth 2007). Formulations are a principal means participants use to display and secure that their interactions are self-explicative, intelligible and accountable events.

(b) Heritage and Watson (1979) noticed that formulations are designed and treated in different ways depending on if they are produced by a news deliverer or a news recipient. They restrict their treatment to formulations which are produced as responsive actions and which make confirmation by the producer of the original version relevant. Most research in CA has adopted this more narrow use of "formulations" (e.g., Heritage 1985; Beach and Dixson 2001; Drew 2003; Antaki et al. 2005; Hutchby 2005; Barnes 2007; Antaki 2008). Virtually all studies focus on functional aspects of formulations. They show that formulations are used by institutional agents as means to transform (laypersons') accounts according to institutional relevancies, such as arriving at a diagnosis, focusing on therapy-relevant matters, facilitating agreement in meetings, or committing interviewees to more newsworthy claims (Drew 2003). Although they are produced as seemingly innocent displays and checks of understanding, formulations are powerful rhetorical means. Since formulations are often used to pin down relevant outcomes of topical talk, on which ensuing talk builds, and to close topics, they can be used to steer the interaction without making perspectives and goals of their producers explicit (Antaki 2008). In this Special Issue, the paper by Deppermann aligns with this use of "formulations". 
(c) Still another notion of "formulation" has been put forward by Schegloff (1972: 80 ), who defines "formulations" as "places in conversation where an object (including persons) or activity is identified". Schegloff is interested in how people choose a location formulation under particular interactional circumstances characterized by a specific constellation of speaker, hearer's knowledge, referent, situation of speaker and hearer in relation to each other and to referents, topic and common activity. Schegloff is dealing with basic issues of interactional semantics, because the selection problem arises from the fact that there are myriads of ways to refer correctly to the same referent. Still, only some formulations may be used relevantly under given interactional circumstances and each formulation may give rise to specific inferences in addition to making referents identifiable. With its more general meaning, Schegloff's notion aligns with the common-sense meaning of "formulation" in terms of "how things are put into words" Bilmes (this volume), and is related to psycholinguistic theories of formulation (Formulierungstheorie, Antos 1982). Sacks' usage of "formulation" in his lectures (Sacks 1992) is, for the most part, similar to Schegloff's, although perhaps more general.

In contrast to the other two versions of "formulation," Schegloff's notion does not include that formulations must link back to some prior version of things talked about. Still, all three approaches deal with descriptive practices, because the relationship of aboutness is crucial for "formulations" in each sense. They inquire into the practices and preferences, determinants and functions of various ways to refer to referents, events, states of affairs, experiences, and actions.

The three papers in this volume approach formulations by comparing first and subsequent versions of talk about some referent, state of affairs, etc. in an interactional episode. Such comparisons elucidate the semantic work carried out by participants in an interactional sequence. They make locally relevant semantic properties of linguistic items available which may not be evident when no second (or nth) version is formulated. Subsequent variants of reference and description in interaction show that every formulation

- is selective and aspectual: it focuses specific properties of referents at the dispense of others and, in doing so,

- is contingent: it is a possible, but not a necessary way of formulating the referent and its properties;

- purports to be relevant: the selection of a formulation among possible others is made with respect to (perspectival, participant-sensitive) pragmatic requirements and purposes (together with its contingency, this also means that formulations are disputable in terms of relevance, even if they are unquestionably true);

- is inference rich: it contextualizes other states of affairs, consequences, assessments, positionings of self and others, etc., which are presupposed by or which typically co-occur with the use of the formulation;

- is constructive: it provides a way of seeing things, i.e., it conceptualizes the situation talked about in a certain way (cf. Heritage and Watson 1979; Drew 2003; Antaki 2008). 
Before we turn to semantic properties of formulations, we first consider some requirements for studying semantics within the framework of CA.

\section{Studying Interactional Semantics: Sequential Analysis and Beyond}

As Bilmes (this volume) states, the study of formulations is distinctive within the enterprise of CA with its focus on the "rhetorical and reality-constructive aspects of linguistic action". Bilmes makes a plea for studying the "organization of meaning in conversation" in addition to the study of the "organization of turns and actions". This neither means that the usual concern of CA with the sequential organization of talk is suspended nor that meaning is divorced from action. Rather, rhetorical design and persuasive effects, indexing contextual knowledge and conversational inferencing have to be shown to be exhibited by and within the talk itself and as part and parcel of what formulations mean and do in the interaction.

This view has not always been common-sense in CA. Historically, the study of meaning in CA was taken to be the business of membership categorization analysis (MCA; Sacks 1972, 1992; Jayyusi 1984; Hester and Eglin 1997), which was associated with the analysis of membership categorization devices as members' knowledge of social structure. However, Watson (1997) already pointed out that categorization and sequence are reflexively related to each other: Categorizations obtain at least part of their meanings from the interactional sequence they occur in, while, at the same time, they are building blocks (of the meanings) of the sequences which define their local meanings. Hauser (2011, this volume) shows how formulations used to categorize members and their meanings are locally occasioned by actions, argumentative, referential and topical contexts established in the interactional sequence, while knowledge about membership categorization devices, which ranges far beyond the interactional situation, is necessary for the situated interpretation of categorization terms as well.

In all contributions to this Special Issue, the study of subsequent versions of reference and descriptions in their sequential context is used as the core method of interactional semantics. Generalization and abstraction is not studied as a feature of items in isolation (like abstract vocabulary, terms of low granularity), but as situated, sequential practice in which one formulation is abstracted, generalized to another one (or the other way round, specified, exemplified). E.g., a description of a person's action is generalized by ascribing features to the category the person belongs to (Hauser 2011, this volume), a description of some experience is abstracted by warranting a more general attribution of a psychological state or property of the experiencer (Deppermann 2011, this volume). Such sequential, relational actions allow to see how generalization/abstraction are used, i.e., what they do in the local context compared to the less general, less abstract versions. In this way, sequential analysis can show how generalization and abstraction are adapted to action and topic, how semantic and inferential aspects are attended to and negotiated by responses, how contrasts are used to highlight locally relevant semantic aspects, how (narrative) exemplification and repair are used to clarify meanings, etc. As with other issues of interactional organization, sequential analysis 
aims to show how meaning is displayed and constructed as an observable, sequential, intersubjective phenomenon (Schegloff 1992a).

Still, sequential analysis does not allow us to capture all aspects of meaning which matter to participants in situ. Participants do not display all locally relevant semantic properties of (lexical) items by the way they design and place their turns at talk. Of course, we are not dealing here with aspects of meaning which matter from a diachronic point of view or which a psycholinguist would find to be properties of the mental lexicon. What we are interested in is to get a grip on those aspects of interactional meaning which account for when, why and for what purpose some item is used, when sequential analysis does not yield sufficient answers or only gives us a hint that an item has some (problematic, embarrassing, argumentative, etc.) interactional properties without giving us access to the semantic basis of these properties. In other words, participants rely on a background of knowledge and understanding, which is not displayed in talk, but which lays the base for what can be accomplished with talk. This order of implicit understandings is not a cognitive reality divorced from observable talk, which does not matter for interactional semantics. Rather, what is implicitly, but recognizably displayed by and for participants in interaction can often only be recovered if the analyst brings cognitive and cultural background assumptions which participants can be held to share to bear on sequentially organized interaction. Indeed, it is one of the basic findings of research on formulations, that semantic and rhetoric properties of formulations can only be grasped when compared to "possible alternatives," which are equally correct in truth-conditional terms (cf. Edwards 1997).

Of course, researchers in CA often have used background knowledge in order to elucidate what is going on in an interactional sequence (see, e.g., Heritage and Raymond 2005; Schegloff 1992b). The study of interactional semantics, however, forces the analyst not only to do so, but also to be methodologically explicit about how cultural and cognitive background enters the analysis, because part of the structures to be explicated have to be described with reference to this background.

Bilmes (2008, this volume) and Deppermann (2000) claim that sequential CA has to be complemented with ethnography when dealing with semantics in interaction. Indeed, reflections on how to reconcile CA and ethnography (see also Moerman 1988; Bilmes 1996; Maynard 2003) in most cases started from an interest in dealing with matters of meaning in interaction. Ethnographic background is needed to discover how interactional histories are reflected by the choice of a formulation, which contexts it makes available, how it meaningfully contrasts with what others (could) have said, how institutional agendas and professional knowledge are indexed by formulations. Ethnography is not only necessary for enriched understanding. The explication of the workings of interactional semantics forces the researcher to be more explicit than is usual in CA in stating ethnographic facts, in explicating them as part of the encyclopedic meaning of expressions used and in showing how they provide an inferential basis for local practices of sense-making (cf. political and cultural background in the analyses by Hauser (2011, this volume); see also Bilmes 2008). To be sure, ethnography should not be used simply as an addendum to CA "in order to give some flavor of the context" or applied in a deductive fashion, imbuing conversational data with ethnographically prefigured 
interpretation. Rather, the analyst has to show that ethnographic background in fact is needed for a better understanding of the data. Evidence for this is

- the discovery of orders of coherence in the interaction which are otherwise unavailable,

- noticing innuendo and interactional subtleties which would go by unnoticed otherwise,

- being able to make sense of interactional phenomena which would be unintelligible without ethnographic background,

- being able to decide among competing interpretations on ethnographical grounds,

- enriching the analysis by elucidating functions and epistemic backgrounds of participants' choices (Deppermann 2000).

Hauser's analysis in this Special Issue beautifully shows how CA-inspired research on semantics in interaction needs to make use of ethnography, while clearly distinguishing this requirement from aspects of ethnographic knowledge which may be relevant for other purposes, but which do not contribute to the analysis of the semantics of categorization and generalization in his data.

The need for ethnography combines with the need for comparing actual choices in talk with possible alternative formulations. Already Schegloff's (1972) seminal study on location formulations crucially rests on paradigmatic contrast sets of possible formulations, which are equally correct in truth-conditional and referential terms, in order to tease out the precise semantic, inferential and recipient-designed properties of some formulation under study. The latter can only be revealed by showing that the formulation does things which the other formulations do not or, just to the contrary, that it does not lend itself to ("avoids") interpretations which possible alternatives make available. Bilmes (2008) compares actual data with taxonomic alternatives in order to account for properties of the level of generality of the formulation chosen and for its precise functional rationale. Comparative techniques like these resemble opposition paradigms of the structuralist tradition. Still, what counts as a relevant possible contrast is not a matter of options provided for by an abstract system (of language). It is rather the range of options which are relevant in the situation, i.e., which can be used to refer to the same referent, to deal with the same interactional problem, to address the same topic etc., depending on which practical task and which features of referential and epistemic context matter for the participants in situ. This becomes most obvious if ad-hoc-categories (like in Hauser's data) are created or if indexical expressions like "we" (and not categorylabels) are used. A more systematic treatment of the different kinds of comparison with "possible alternatives" and of the uses of this methodological procedure within $\mathrm{CA}$ is beyond the scope of this paper, but would definitely be in place (see Deppermann 2008: 90-94 for some reflections on this issue). A more thorough treatment of the matter would also need to relate the methodological option of using "possible alternatives" to the CA-practice of working with collections of data of factual variation of a device.

In terms of theory, the above methodological considerations suggest that CA needs to enter into dialogue with MCA (Schegloff 2007), taxonomic analysis 
(Bilmes 2008, 2009; this volume), Gricean pragmatics (Bilmes 1993; Deppermann 2005; 2011, this volume), and frame semantics (Deppermann 2005) in order to account for inferences and implicit meanings to be recovered as part of interactional semantics.

\section{Semantic Aspects of Formulations}

Meaning in interaction is tied to communicative intentions as they are made publicly available by speakers' actions and to understandings as evidenced by recipients' responses. Meaning is situated, rhetorical, informed by pragmatic concerns, negotiable, and open-ended in terms of explicability (see, e.g., Garfinkel 1967; Edwards 1997). Same-speaker formulations, which rework a prior version of reference or description, are used to explicate, clarify, specify, generalize, etc. meanings; other-speaker formulations are displays of understanding (and can clarify, explicate, etc. as well). Still, in neither case are formulations a transparent means of elucidating meanings. Formulations have both an explicative and a transformative aspect: While each formulation preserves parts of the meaning established before, it deletes other parts and adds new aspects of meaning (Heritage and Watson 1979: 129). In addition, there is a reflexive relationship between first and second versions: Formulations make meanings explicit which were implicit in the prior version (or which are at least treated as if they had been implicated in it), but their local meaning rests itself in part on the versions they are meant to replace (see Deppermann and Hauser 2011, this volume). When studying semantic properties of formulations, it is important to attend both to the sequential organization and the precise linguistic design of the formulation.

- Sequentially, same-speaker formulations must be distinguished from otherspeaker formulations. Formulations within the same multi-unit turn as the first version can be projected, e.g., by story-prefaces which introduce a categorization that is unpacked in the story (see Deppermann 2005). They need to be distinguished from responsive self-formulations (in third or later positions), which react to recipients' responses to the first version (reasserting, clarifying, accounting for it, etc.).

- Among other-speaker formulations, practices of formulation differ in terms of the displayed presumption of intersubjectivity of formulated meanings. The speaker who produces the formulation may index that $\mathrm{s} / \mathrm{he}$ assumes that his/her formulation explicates or paraphrases the meaning which the prior speaker meant to communicate. In English, this is mostly done with so-prefaced formulations (see Raymond 2004), in German with also-prefaces (see Deppermann 2011, this volume). Alternatively, the formulation may be framed as a unilateral inference, i.e., an understanding which does not purport to explicate what the prior speaker meant, but some subjective interpretation, noticing, or an upshot which is relevant with respect to the speaker's own agenda. In German, dann-prefacing, first person mental verbs and hypothetical constructions are used to index unilateral formulations. An intermediate case is, e.g., what 
Heritage (1985: 108) calls an "inferentially elaborative probe," which pushes the formulated position to an extreme, thus making it more newsworthy.

- Formulations can deal with semantic units of different size and kind. They can be used to formulate the meaning of single words and phrases used before (Bilmes this volume), statements (Hauser 2011, this volume) or descriptions and narratives (Deppermann 2011, this volume). They can also categorize what was being done earlier in terms of individual or collective action (see, e.g., Bilmes 1981).

Depending on sequential relationship, linguistic-design and referential scope, formulations may have a different semantic status regarding the first version.

\section{Generalization and Abstraction as Practices of Formulation in Interaction}

Generalization and abstraction have to do with granularity of categorizations and their hierarchical place within taxonomies (Bilmes 2008, 2009; Schegloff 1972; 2000). The taxonomic approach (see, e.g., Tyler 1969) is static and has an objective flavor, suggesting that taxonomies are clear-cut cognitive, set-logical structures, which simply reflect relationships of class-inclusion between terms. The papers in this Special Issue, however, study generalization and abstraction as semantic relationships which are accomplished in interaction by generalizing and abstracting formulations of prior versions. In interaction, taxonomies are not simply invoked, but they are actively constructed. This is most obvious with ad hoc-taxonomies (see Hauser 2011, this volume; Barsalou 1983). But also taxonomic relationships which belong to cultural stocks of knowledge need to be made relevant selectively and locally, because there is never only one path of possible abstractions without alternative. Each categorization can be abstracted according to multiple taxonomic relations, suggesting other co-selected categorizations as relevant contrasts. So, the interesting question is: "What taxonomy?" (Bilmes 2008: 200). In addition, abstraction/generalization always realize a certain level of granularity, which is neither predetermined by the things talked about nor by the existence of some taxonomy as such. There is always a magnitude of categorizations of varying granularity, which can be applied correctly to a referent in truth-conditional terms. Truth-conditional correspondence does not determine which level of taxonomic granularity will be used in an occasioned formulation. So, the second question regarding the speaker's choices is: "What level in the taxonomic hierarchy?" (Bilmes 2008: 201). "The actual use of categories is not simply a matter of actuating some pre-existing cognitive structure; rather, the taxonomic direction and level chosen is fitted to the local occasion of use" (Bilmes 2008: 209).

Abstraction implies that aspects of a first version are selectively focused on in a second version, doing away with some of its indexical detail. This is most obvious with notionalizations, which turn (sometimes lengthy) descriptions into condensed, abstract, timeless, and often agentless categorizations expressed by a nouns or phrases (Deppermann 2011, this volume). Abstraction may, but need not imply generalization. Abstraction may only mean focusing on and singling out what is 
relevant. Moreover, it can be used to convey that a previously described local, single instance is taken to stand for a more general pattern or state of affairs to hold. Notionalizations suggest a realm of enduring representations, because they distill reifications of abstract concepts, processes, experiences etc., captured by nouns, from the fleeting vicissitudes of interaction. By virtue of these qualities, they are apt for topical closure and may become emergent keywords, which can be used to pin down and re-contextualize topical issues and interactional histories efficiently, becoming canonical ways of referring in the future interaction.

Generalization and abstraction are practices of semantic work. Although they transform the meaning of prior first versions, their local semantics still builds on the meanings of the prior items which become abstracted, generalized, specified, exemplified, etc. This is especially so, because the more general and abstract categorizations are, the more vague they tend to be as such. Thus they are in need to be constrained and anchored in the present context. E.g., Deppermann (2011, this volume) shows how therapists' abstract psychologizing formulations derive their reference from patients' experiential narratives and argumentations, Hauser (2011, this volume) discusses how categorical generalization is a means to understand the identity of the individual person, while the more general category is elucidated by properties and actions of the individual, on which it is (sequentially and epistemically) based. In their situated use, generalization and abstraction thus are subject to and means of documentary interpretation (Mannheim 1980; Garfinkel 1967), accounting for particular instances by more general patterns, which themselves get their referential and indexical meaning by the instances they are applied to.

This documentary reflexivity provides abstraction and generalization with a pseudo-explanative flavor: In transcending the individual case, generalization and abstraction suggest that the individual case gets accounted for, i.e., explained, in more general terms. Professional formulations, using abstract terms belonging to languages for special purposes (e.g., in medicine, psychotherapy), make abundant use of this property (see Deppermann 2011, this volume). Because of their explanative value, abstraction and generalizations are mostly used in contexts which are overtly (meetings, discussions, advice-giving) or more implicitly (personal narratives, gossiping, diagnosing) argumentative. It is worth noting that sequential order matters: Generalization and abstraction are used to conclude, close topics, explain and retain relevant aspects for future treatment, and to strengthen and justify a claim regarding individual cases; specification, i.e., the exemplification of a more general or abstract categorization or claim, is used to justify by giving evidence or to repair on understanding problems. There is a reflexive relationship between semantic and argumentative issues: Exemplifications both provide evidence for generalizations and elucidate part of their meanings; generalizations both account for the properties of instances and imbue them with meaning in terms of categorizing them as an instance of a more general category (cf. Deppermann 2005). This explanative-explicative tension can border on circularity, in particular, if observations of actions or events are transformed into dispositional predicates derived from the very instances they purport to explain (cf. already Ryle 1949). 
Abstraction and generalization are typical of professional formulations. Subsuming particular instances under professional categories, which abstract from casebased indexicalities like spatial, temporal, personal, etc. particulars, lies at the heart of professional practice. Generalizing formulations secure the intelligibility of experience by demonstrating the applicability of general patterns, suggesting that situated experience is accountable and thus treatable according to known procedures.

Generalization and abstraction partake in several orders of reflexivity. They reflect

- institutional speakers' discourse and situated identities (Zimmerman 1998), because the activity of formulating and the lexical choice of generalizing and abstracting formulations are often category-bound activities tied to institutional identities (cf. Drew 2003) and as such constitutive of their talking into being (cf. Heritage and Clayman 2010).

- The paradoxical status of clients of an institution: They need to confirm formulations, but not to provide them. Formulations reflect how institutional agents depend on cooperation and input by the client, while simultaneously exerting professional authority. Formulations attest to the split epistemic asymmetry of expert-laymen interactions, both in terms of linguistic design and of interactional organization: The client is knowledgeable regarding what happened, the professional regarding its abstract and generalizable categorization.

- Institutional concerns: Their design orients to practical relevancies, such as providing a and subsuming to a professional perspective (Hutchby 2005; Deppermann 2011, this volume), closing topical sequences and fixing their outcomes (Barnes 2007), shaping prior talk so as to become a suitable basis for next actions to be performed (Antaki 2008; Hutchby 2005; Beach and Dixson 2001), reducing abundant complexity of arguments by summarizing (Deppermann and Spranz-Fogasy 1998). Doing so, formulations in turn are basic practices to get institutional work observably being done in interaction.

- Genre and activity type. E.g., formulations in psychotherapy transform patients' narratives of experiences into evidence of general types of psychological problems and dispositions. In a similar vein, general formulations in prefaces or codae of stories transform story-events into evidence of the personality of the story-protagonist or of the morale of a type of event. So, as the design of formulations is adapted to genre and activity type, they are also constitutive of bringing an instance of the very genre/activity they are adapted to recognizably into being.

\section{Conclusion}

Prior research has gained rich insight into sequential organization and interactive functions of formulations in various types of institutional settings. Still, we now very little about the precise turn-constructional formats of formulations, the 
language-specific resources used for them and how these design-features relate to what formulations do and mean in the interaction. There are at least two important issues which deserve more research in this respect:

(a) The nature of the semantic operations and transformations people produce in formulating as part of their everyday semantic work. This is also because formulations provide for a rich and methodologically promising key to semantics in interaction.

(b) The display of epistemic claims relating to subjectivity, intersubjectivity, independent or superior knowledge, (un)certainty, etc. in formulations. Formulations are one of the major sites of displaying understanding and epistemic stance vis-à-vis co-interactants,

The contributors to this Special Issue would be glad if their papers work as to inspire further research along these lines.

\section{References}

Antaki, C. (2008). Formulations in psychotherapy. In A. Peräkylä, C. Antaki, S. Vehviläinen, \& I. Leudar (Eds.), Conversation analysis and psychotherapy (pp. 107-123). Cambridge: CUP.

Antaki, C., Barnes, R., \& Leudar, I. (2005). Diagnostic formulations in psychotherapy. Discourse Studies, 7(6), 627-647.

Antos, G. (1982). Grundlagen einer Theorie des Formulierens_Foundations of a theory of formulation. Tübingen: Niemeyer.

Barnes, R. K. (2007). Formulations and the facilitation of common agreement in meetings talk. Text and Talk, 27(3), 273-296.

Barsalou, L. W. (1983). Ad hoc categories. Memory \& Cognition, 11, 211-227.

Barth-Weingarten, D., Reber, E., \& Selting, M. (Eds.). (2010). Prosody in interaction. Amsterdam: John Benjamins.

Beach, W., \& Dixson, C. (2001). Revealing moments: Formulating understandings of adverse experiences in a health appraisal interview. Social Science and Medicine, 52, 25-45.

Bilmes, J. (1981). Proposition and confrontation in a legal discussion. Semiotica, 34(3/4), 251-275.

Bilmes, J. (1993). Ethnomethodology, culture, and implicature: Toward an empirical pragmatics. Pragmatics, 3, 387-409.

Bilmes, J. (1996). Problems and resources in analyzing Northern Thai conversation for English language readers. Journal of Pragmatics, 26(2), 171-188.

Bilmes, J. (2008). Generally speaking. Formulating an argument in the U.S. Federal Trade Commission. Text \& Talk, 28(2), 193-217.

Bilmes, J. (2009). Taxonomies are for talking: Reanalyzing a Sacks' classic. Journal of Pragmatics, $41(8), 1600-1610$.

Bilmes, J. (this volume). Occasioned semantics: A systematic approach to meaning in talk. Human Studies, 34(2).

Bührig, K. (1996). Reformulierende Handlungen.—Refomulating actions. Tübingen: Narr.

Ciapuscio, G. E. (2003). Formulation and reformulation procedures in verbal interactions between experts and (semi-)laypersons. Discourse Studies, 5(2), 207-233.

Couper-Kuhlen, E., \& Ford, C. (Eds.). (2004). Sound patterns in interaction. Amsterdam: John Benjamins.

Couper-Kuhlen, E., \& Selting, M. (Eds.). (2001). Studies in interactional linguistics. Amsterdam: John Benjamins.

Deppermann, A. (2011). Notionalizations: The transformation of descriptions into categorizations. Human Studies, 34(2).doi:10.1007/s10746-011-9186-9. 
Deppermann, A. (2000). Ethnographische Gesprächsanalyse: Zu Nutzen und Notwendigkeit von Ethnographie für die Konversationsanalyse.-Ethnographic conversation analysis. On the uses and necessities of ethnography for conversation analysis. Gesprächsforschung, 1, 96-124. http://www. gespraechsforschungozs. http://de/heft2000/ga-deppermann.pdf. Accessed 22 June 2011.

Deppermann, A. (2005). Conversational interpretation of lexical items and conversational contrasting. In A. Hakulinen \& M. Selting (Eds.), Syntax and lexis in conversation (pp. 289-317). Amsterdam: John Benjamins.

Deppermann, A. (2007). Grammatik und Semantik aus gesprächsanalytischer Sicht.-Grammar and semantics form a conversation analytic point of view. Berlin: de Gruyter.

Deppermann, A. (2008). Gespräche analysieren.-Analyzing conversation. Wiesbaden: VS.

Deppermann, A., \& Spranz-Fogasy, T. (1998). Kommunikationsstörungen durch den GesprächsprozeßZur Entstehung von Interaktionsdilemmata durch zeitliche Komplexierung.-Communication problems as effects of the conversational process. In Fiehler, R. (Ed.), Verständigungsprobleme und gestörte Kommunikation.-Problems of understanding and Miscommunication (pp. 44-62). Wiesbaden: Westdeutscher Verlag.

Drew, P. (2003). Comparative analysis of talk-in-interaction in different institutional settings. In P. Glenn, C. LeBaron, \& J. Mandelbaum (Eds.), Studies in language and social interaction (pp. 293-308). Mahwah, NJ: Erlbaum.

Edwards, D. (1997). Discourse and cognition. London: Sage.

Garfinkel, H. (1967). Studies in ethnomethodology. Englewood Cliffs, NJ: Prentice-Hall.

Garfinkel, H., \& Sacks, H. (1970). On formal structures of practical action. In J. C. McKinney \& E. A. Tiryakian (Eds.), Theoretical sociology (pp. 338-366). New York: Appleton-Century-Crofts.

Gülich, E., \& Kotschi, T. (1996). Textherstellungsverfahren in mündlicher Kommunikation.-Procedures of producing texts in oral communication. In W. Motsch (Ed.), Ebenen der Textstruktur.-Levels of text structure (pp. 37-80). Tübingen: Niemeyer.

Hakulinen, A., \& Selting, M. (Eds.). (2005). Syntax and lexis in conversation. Amsterdam: John Benjamins.

Hauser, E. (2011). Generalization: A practice of situated categorization in talk. Human Studies, 34 (2). doi:10.1007/s10746-011-9184-y.

Heritage, J. (1985). Analyzing news interviews. In T. A. van Dijk (Ed.), Handbook of discourse analysis. Vol. 3 (pp. 95-117). London: Academic.

Heritage, J., \& Clayman, S. (2010). Talk in action. New York: Wiley-Blackwell.

Heritage, J., \& Raymond, G. (2005). The terms of agreement. Indexing epistemic authority and subordination in talk-in-interaction. Social Psychology Quarterly, 68, 15-38.

Heritage, J., \& Watson, D. R. (1979). Formulations as conversational objects. In G. Psathas (Ed.), Everyday language (pp. 123-162). New York: Irvington.

Hester, S., \& Eglin, P. (Eds.). (1997). Culture in action. Studies in membership categorization analysis. Washington, DC: University Press of America.

Hutchby, I. (2005). "Active listening": Formulations and the elicitation of feelings talk in child counselling. Research on Language and Social Interaction, 38(3), 303-329.

Jayyusi, L. (1984). Categorization and the moral order. Boston, MA: Kegan \& Routledge Paul.

Linell, P. (2009). Rethinking language, mind, and world dialogically. Charlotte, NC: Information Age Publishing.

Mannheim, K. (1980[1922-1924]). Structures of thinking. London: Routledge \& Kegan Paul.

Maynard, D. W. (2003). Bad news, good news. Conversational order in everyday talk and clinical settings. Chicago, IL: U Chicago P.

Moerman, M. (1988). Talking culture-ethnography and conversation analysis. Philadelphia, PA: U Pennsylvania P.

Norén, K., \& Linell, P. (2007). Meaning potentials and the interaction between lexis and grammar. Pragmatics, 17, 387-416.

Raymond, G. (2004). Prompting action: The stand-alone "so" in ordinary conversation. Research on Language and Social Interaction, 37(2), 185-218.

Rittgeroth, Y. (2007). Reformulierungen im aufgabenorientierten Dialog.-Reformulations in taskoriented dialogue.-(Doctoral dissertation.) Bielefeld: Fakultät für Linguistik und Literaturwissenschaft der Universität. http://bieson.ub.uni-bielefeld.de/volltexte/2007/1058/pdf/Reformulierungen_ im_aufgabenorientierten_Dialog.pdf.pdf. Accessed 18 May 2011.

Ryle, G. (1949). The concept of mind. Chicago, IL: U Chicago P. 
Sacks, H. (1972). On the analyzability of stories by children. In J. J. Gumperz \& D. Hymes (Eds.), Directions in sociolinguistics. The ethnography of communication (pp. 325-345). New York: Holt, Rinehart and Winston.

Sacks, H. (1992). Lectures on conversation. 2 Vols. Oxford: Blackwell.

Schegloff, E. A. (1972). Notes on a conversational practice: Formulating place. In D. Sudnow (Ed.), Studies in social interaction (pp. 75-119). New York: Free Press.

Schegloff, E. A. (1992a). In another context. In A. Duranti \& C. Goodwin (Eds.), Rethinking context. Language as an interactive phenomenon (pp. 191-227). Cambridge: CUP.

Schegloff, E. A. (1992b). Repair after next turn. The last structurally provided defence of intersubjectivity in conversation. American Journal of Sociology, 97(5), 1295-1345.

Schegloff, E. A. (2000). On granularity. Annual Review of Sociology, 26, 715-720.

Schegloff, E. A. (2007). Categories in action: Person-reference and membership categorization. Discourse Studies, 9, 433-461.

Tyler, S. (Ed.). (1969). Cognitive anthropology. New York: Holt, Rinehart and Winston.

Watson, R. (1997). Some general reflections on categorization and sequence in the analysis of conversation. In S. Hester \& P. Eglin (Eds.), Culture in action. Studies in membership categorization analysis (pp. 49-76). Washington. DC: University Press of America.

Zimmerman, D. H. (1998). Identity, context and interaction. In C. Antaki \& S. Widdicombe (Eds.), Identities in talk (pp. 87-106). London: Sage. 